\title{
O CORPO TRANSITA NO VIEWPOINTS - O VIEWPOINTS TRANSITA NO CORPO: OCORRÊNCIAS POSSÍVEIS PARA O CORPO COMO ARTE ${ }^{I}$
}

\author{
Sandra Meyer Nunes ${ }^{2}$ \\ Volmir G. Cordeiro ${ }^{3}$
}

\begin{abstract}
PALAVRAS-CHAVES: Corpo, ambiente, cena, procedimento artístico, identidade, singularidade.Viewpoints.
\end{abstract}

\section{RESUMO}

Este estudo apóia-se numa investigação artística que toma o corpo como o lugar da ação, de ocorrências e trânsito de informações e como espaço de produção de conhecimento. As teorias contemporâneas sobre o corpo aqui abordadas, propiciam a compreensão das relações que este estabelece com o ambiente e o reconhecimento das formas de organização elaboradas pelo corpo na sua história e na construção de sua identidade. Os processos de criação de intérpretes-criadores na atualidade são problematizados por meio do Viewpoints (Pontos de Vista), procedimento norte-americano desenvolvido pelas diretoras Anne Bogart e Tina Landau para habilitar atores-bailarinos e performers para a cena. Estes processos são construídos no "sempre-presente" com aquilo que se torna materialidade cênica e se desdobra como obra artística na relação corpo-ambiente.

\section{INTRODUÇÃO}

O corpo está (mais uma vez) em questão. Muitos recortes temáticos foram elaborados no sentido de buscar entender as questões diversas relacionadas ao corpo no século XX, especialmente a partir da década de 1970. Neste artigo, considero a perspectiva de questionar conhecimentos já previamente estabilizados sobre o modo de pensar o corpo. Neste sentido, o corpo passa a ser pensado não mais como um recipiente onde informações são depositadas,

\footnotetext{
${ }^{1}$ Relatório final apresentado como término do projeto "O corpomente em cena: as ações físicas do ator-bailarino", desenvolvido no Centro de Artes da Universidade do Estado de Santa Catarina.

${ }^{2}$ Professora Dra do Centro de Artes da Universidade do Estado de Santa Catarina. Doutora em Comunicação e Semiótica pela PUC-SP.

${ }^{3}$ Acadêmico do curso de graduação de Licenciatura em Artes Cênicas e Bolsista de Iniciação Científica-PROBIC do projeto "o corpomente em cena: as ações físicas do ator-bailarino".
} 
onde somente a cultura inscreve seus dados e o corpo se porta como um simples receptáculo, que retém ou aprisiona informações, mas como uma via de trânsito, como um espaço mutável onde as novas informações são processadas e "negociadas" com aquelas que já singularizam a história de cada corpo.

Não mais entendido como um objeto ou instrumento, a espera de ser manipulado por algo ou alguém fora dele, o corpo é percebido sempre em trânsito. Em cada situação que lhe é dada, informações são acionadas para reagir, confluir e formar a si mesmo e o ambiente, como esclarece Pedro Entralgo, “o corpo é o corpo na sua circunstância” (JANA, 1995, p.57).

Greiner, ao citar Prigogine, sintetiza a condição do ser vivo como uma estrutura sempre em estado de reconfiguração, o que ele nomeou como "estrutura dissipativa":

Para Prigogine todos os seres vivos são dissipativos, tudo o que dizemos, as informações do ambiente, nosso sistema de conhecimento, nada disso é imutável. Tudo que é vivo deve cohabitar com a desordem e a instabilidade. Não há escolha. Esta é a natureza do vivo. Assim, no que diz respeito ao corpo, para estudar um regime de atividade corporal é preciso estudar a estabilidade e a instabilidade que, em certas circunstâncias, têm uma configuração e em outras são modificadas. (Apud GREINER, 2005, p. 39).

Na medida em que o corpo transita no espaço e no tempo, constrói história e identidade. Pensar sobre história e identidade se faz aqui necessário quando entendidas como informações selecionadas pelo corpo, categorizadas por seu sistema peculiar e sempre passível de novas configurações. Um corpo vivo, ativo e em processo, que se dá em relação, encontros e desdobramentos com o seu meio.

O desenvolvimento e o entendimento da identidade acontecem com as experiências do corpo, em relação aos eventos já vividos, aos trajetos feitos, às escolhas que são determinadas socialmente, dentre outros aspectos. Nesta rede de acontecimentos, ocorre um processo de consciência “de si mesmo" que dependente das situações vivenciadas e dos experimentos do como ser e estar no mundo.

A experiência do próprio corpo dá-me o meu existir, ou melhor, o modo de estar existindo. Porém, esse 'dar' não se constitui apenas no corpo em si mesmo, mas sim na teia de relações em que sempre o corpo está mergulhado".(JANA, 1995, p. 57). 
Então, numa via sempre em fluxo, corpo e ambiente se fazem. Sob o ponto de vista desse estudo, os dois se complementam como sistemas organizacionais e isso se dá por contaminação oriunda da convivência. Há, portanto, no contágio entre corpo e ambiente, lugar para interferências e variáveis, constituindo uma multiplicidade, aqui referente ao princípio de Deleuze e Guatarri, elucidada no seguinte exemplo:

Uma boa maneira de compreender esta idéia de multiplicidade é olhando uma marionete, os fios e o manipulador: os fios de uma marionete constituem a multiplicidade, nem o que controla, nem o boneco controlado com as cordas, mas as próprias cordas, que comunicam uma parte à outra. (CABRAL e BORGES, 2008).

Em estado de mediação, o corpo acumula experiências, e estas, por sua vez, se dão em acordo com as ações que o corpo realiza no ambiente, que se reconstitui num diálogo constante e dinâmico. Citando a filósofa Sheets-Johnstone, Greiner (2003) contribui para o entendimento da questão:

Cada corpo vivo se constrói, a cada instante, como certa espécie de padrão ou modelo semântico. Mas este modelo é emergente da ação e não dado a priori. Os conceitos são gerados ou tornados conscientes pelo corpo vivo no curso da vida diária por meio de ações como mascar, urinar, respirar, etc. Assim como ações dão origem a novos conceitos, novos conceitos incitam ações. (GREINER; AMORIM, 2003, p.144)

Amparado por este entendimento, pode-se então relacionar o corpo com a composição de sua corporeidade ${ }^{4}$, entendendo-a basicamente como variações comportamentais relacionadas a uma rede de ações e modos de sobreviver que se dão num contínuo processo, onde estão os diferentes estados do corpo, que vivo, age no mundo e potencializa singularidade. "SemprePresente" no mundo e em ação, a corporeidade se constrói no estado de relação, que pressupõe um "estar entre", como mediação de uma rede que impulsiona significados que regem os padrões de relacionamentos. A informação recebida pelo ambiente não é simplesmente

\footnotetext{
${ }^{4} \mathrm{O}$ filósofo francês Michel Bernard, em seus escritos sobre a dança, utiliza o termo corporeité (corporeidade) para descrever o corpo como uma rede dinâmica e instável formada por forças motoras, sensoriais e pulsionais, revendo as categorias tradicionais de entendimento do organismo. (BERNARD, 2001).
} 
armazenada, ela age sobre o comportamento do vivo e reloca a condição do ambiente, permitindo-o ser transformado por meio de sua ação corpórea.

\section{O CORPO NO PROCEDIMENTO: O PERCURSO JÁ É FORMATIVO}

Nesta segunda parte, alguns pontos são levantados a partir do Viewpoints (Pontos de Vista) para aprofundar o processo de formação do corpo para a cena, partindo de questões como: modos de se comportar a partir de ações coletivas, relações entre corpo e ambiente e estados corporais e modos de organização de ações na construção de universos simbólicos. Busco entender o trânsito entre o procedimento técnico sugerido pelo Viewpoints e as possibilidades de apropriação destes pelo intérprete-criador.

O modo como construímos nossos conceitos revela o modo como "propriopercebemos" o mundo. Isto nos dá pistas para compreender como se dá o trânsito entre o pensamento próprio e a lógica exclusiva de organização do intérprete-criador diante do procedimento artístico.

$O$ Viewpoints (Pontos de Vista), organizado e veiculado pelas diretoras americanas Anne Bogart e Tina Landau, embasado pela sua publicação The Viewpoints Book. A practical Guide to Viewpoints and Composition (2005) $)^{5}$, suscita que qualquer criação tenha como partida o tempo e o espaço envolvendo nove abordagens: andamento, duração, repetição, relação sinestésica, topografia, arquitetura, gesto, forma e relação espacial.

O Viewpoints pode ser facilmente lido como um guia de exercícios voltados para a improvisação. Bogart (2005) investiga procedimentos não-hierárquicos e colaborativos, desenvolvendo um treinamento que permite o contato com as sensações/sentimentos através do físico, da voz, do texto e da imaginação. O Viewpoints possibilita escolhas não limitadas a um viés psicológico e individual, propondo ações compartilhadas no tempo e no espaço. $\mathrm{O}$ artista cênico, neste sentido, não se limita a lidar com contextos previamente elaborados, mas constrói novos contextos na relação com outros atores no exercício improvisacional.

O Viewpoints, por este viés, é um "procedimento-ambiente", pois os sujeitos se encontram para o experimento de relações. A partir de um dado, uma condição, o corpo (muitas vezes em pouquíssimo tempo) organiza seu comportamento para aquela circunstância. A prática

\footnotetext{
${ }^{5}$ Tradução: O livro dos Pontos de Vista: um guia prático para os Pontos e Vistas e Composição. O método tem sido estudado pelo grupo de pesquisa da UDESC, coordenado pela Dra Sandra Meyer Nunes, desde 2006 por meio de estudo teórico-prático desse livro. Neste sentido, optamos por manter o termo Viewpoints no idioma inglês.
} 
dos exercícios admite uma abordagem que requer um "saber fazer instantâneo", que se constrói no imediato, sem uma elaboração formal, psicologizada e mesmo planejada. É um lançar-se no "espaçotempo" e ver como estas duas potências conversam com o corpo, fazendo-o agir. Com isso, o Viewpoints possibilita a organização de um pensamento sobre a cena, sobre o feitio do teatro e também da dança, provoca novos conceitos e movimenta mecanismos de criação, onde a abertura de possibilidades não se esvazia nela, mas sim, pretende impulsionar encontros, relações e contatos, permitindo-se ser um campo de desdobramento, de variadas leituras e transporte de idéias.

Anne Bogart e Tina Landau (2005) mencionam em seu guia para a aplicação do Viewpoints, que estes abrem portas para um modo de sentir o mundo, de apreender percepções e desenvolver o senso de observação. Por este caminho, há um reforço que salienta a idéia de um "corpo com o ambiente", em mútua atividade de troca, sem um sujeito que fornece e um objeto que recebe. Por meio das relações provenientes do encontro corpo-ambiente, a percepção renova suas estruturas, conquista modos de se envolver com o mundo, envolvendo as outras pessoas, alternando e aprofundando os mecanismos de comunicação.

\section{A AFECÇÃO E O AFETO CORPO-PROCEDIMENTO}

A abertura para o imaginário proporcionada pelo Viewpoints propicia o reconhecimento dos discursos organizados historicamente por cada corpo, como um convite para encontrar com o outro e gerar desdobramentos, contaminando os modos de ação e fomentando a criação com um senso coletivo, não menos particularizado diante das especificidades inerentes ao percurso criativo. $^{6}$

Neste sentido, a criação vai sendo construída permeada por "afecções" de um corpo a outro, onde a constituição do discurso da obra como um todo se faz pela sobreposição dos corpos. Quando se trabalha com um dos Viewpoints, como por exemplo, a arquitetura, evidencia-se um transbordamento da relação espacial, já que a instrução no trabalho com a arquitetura formulada por Bogart (2005) sempre indica conexões com tudo o que envolve o

\footnotetext{
${ }^{6}$ Vale colocar que esta parte também se refere ao modo particular de vivenciar o Viewpoints, como praticante recente do procedimento (iniciado em 2006) no grupo de pesquisa da UDESC.
} 
espaço físico onde os atores se encontram (manuseio de objetos, texturas, relevos) deslocando-o e integrando-o a investigação pessoal na criação do intérprete-criador.

$\mathrm{O}$ termo afecção empregado acima se refere ao affectio de Spinoza, determinado a primeira vista como "o estado de um corpo considerado como sofrendo a ação de um outro corpo" (DELEUZE,1978). O filósofo indica que a afecção ocorre mais no corpo do afetado do que naquele que afeta, categorizando intensidades de afecção. Neste caso, o que mais interessa na obra de Spinoza, e que possa relacionar-se ao Viewpoints, é pensar a afecção como uma "mistura de corpos", a passagem de um sobre outro, a instabilidade gerada neste encontro como propulsão para a construção da obra de arte.

$\mathrm{Na}$ prática do Viewpoints - aqui relacionada ao grupo de pesquisa $\mathrm{O}$ corpomente em cena - uma lembrança é sempre retomada para desenvolver o trabalho com precisão: permitir que o intérprete-criador receba propostas das informações que compõe o espaço de prática. Isso quer dizer, que fica concedido ao corpo do criador, por um determinado momento, menos a tarefa de propor variados materiais, mas sim, de deixar-se ser afetado pelas ações dos outros corpos presentes na sala de trabalho, constituindo outro Viewpoints, a relação sinestésica.

O corpo abordado aqui se refere a tudo aquilo que envolve o encaminhamento para a cena. Temperatura, espaço físico, informações diretamente ligadas ao trabalho ou pessoais levantadas em ensaios, modos de aplicação do exercício Viewpoints ${ }^{7}$, etc, configuram outros "corpos" que colocam o corpo do ator-bailarino para ser afetado, misturado e experimentado nestes encontros, organizando as potências de ações estimuladas por estes.

Há um poder do corpo sobre a afetação dos outros corpos. Saber disto, lembra Spinoza (Apud DELEUZE,1978) é estar em posse da sabedoria. Este poder atribuído ao corpo de que fala o filósofo ocorre no Viewpoints como espaço de percepção e armazenamento de informações que potencializem o desenvolvimento de cada exercício, a cena e seus anteparos, a organização coletiva do grupo e assim por diante.

$\mathrm{Na}$ Viewpoints, tem-se um espaço dotado de afecções onde sistemas comportamentais atuam: as escolhas de como nos movimentamos, as emoções que são acessadas, relações com objetos, temperatura do ambiente e as interações com outras pessoas, esboçam uma matriz

\footnotetext{
${ }^{7}$ Todo coletivo que se reúne para experienciar um procedimento como caminho para habilitar o corpo para a cena passa pelo estado de afecção. Neste caso, faço novamente referência ao trabalho realizado no grupo de pesquisa da UDESC.
} 
global da criação como um todo, que embora não seja explicitada diretamente na cena composta, já está nela e não menos em cada integrante que dela participa.

Sobre estes deslocamentos propostos pelo procedimento que realoca a espécie de ação do ator-bailarino submetido nesta prática, ele acaba por fazer o que Greiner (2003, p.143) diz que ocorre quando o homem age, pois assim, "abre a possibilidade de fazer ou desfazer o que foi conceituado antes, instaurando novas possibilidades de pensar e mover: corpo, idéias e mundo".

Um outro olhar para a percepção pode ser evocado no uso do Viewpoints, deslocando o sentido desta de um registro passivo de sensações para um ativo, que instiga uma ação do performer diante da sensação causada, um levantamento de possibilidades para novas decisões dentro e fora do procedimento de improvisação cênica, "porque toda percepção é a confirmação ou a rejeição de uma hipótese que alguém tem sobre o modo de manifestação ou o comportamento dos outros ou sobre si mesmo" (JANA, 1995, p.63).

De um modo geral, o ator-bailarino está sujeito a um estado de afetação, de um contato sempre presente com outros corpos:

Todo sujeito vivo é primeiro um sujeito afetado, um corpo que sofre de suas afecções, de seus encontros, da alteridade que o atinge, da multidão de estímulos e excitações, que cabe a ele selecionar, evitar, escolher, acolher... Para continuar a ser afetado, mais e melhor, o sujeito precisa ficar atento às excitações que o afetam, e filtrá-las, rejeitando aquelas que o ameaçam (PELBART apud STIEGLER, 2003, p. 72).

Quando acontecido o encontro com um outro modo de ação, uma reinvenção é criada na fronteira entre um e outro, abrindo espaço para um mais recente padrão de ação, gerado pela colisão entre diferentes territórios e, que a partir deste fenômeno, a cultura se refaz para os envolvidos, modificando o modo de estar no mundo.

Insistente nesta prática compartilhada com o ambiente, o ator-bailarino renuncia a uma preparação centrada na racionalidade e/ou intencionalidade objetiva, para então impulsionar seu agir pautado no imprevisível. Isto também quer dizer que trabalhando com o procedimento Viewpoints é possível ainda desenvolver este outro foco sobre o corpo, que o treina e observa sempre em ação, dispondo-o sobre uma rede onde informações que irão aparecer somente no 
momento da realização da ação, trazendo uma singularidade pouco planejada, surpreendendo os envolvidos do processo.

O relacionamento evocado na convivência com o procedimento é de ordem rizomática ${ }^{8}$, fundada pela multiplicidade, dotado de conjuntos que podem ser alterados, renovados, renomeados e deslocados. Para Deleuze e Guatarri o rizoma é:

[...] aberto e desmontável, pode ser conectado em qualquer uma de suas partes ou dimensões, [...], ser (re)construído por um indivíduo ou por uma formação social, como obra de arte ou ação política, como uma meditação. Ele tem entradas múltiplas. (CABRAL; BORGES, 2008).

Estas múltiplas vias de acesso também podem ser encontradas no convívio com o procedimento artístico organizador da multiplicidade pertencente ao corpo em coexistência com o ambiente. Cabral e Borges (2008) complementam:

O rizoma é uma circulação de estados, uma combinação anômala cujos resultados não podemos prever ou organizar, pois ele está sempre em um meio. Um conjunto de devires e sempre um intermezzo - tais seriam as proposições constitutivas de um rizoma, lembrando que o rizoma trata-se de produção de inconsciente e de novos enunciados e de outros desejos.

O entendimento de rizoma favorece uma direta analogia ao Viewpoints, pois este último tampouco tem em vista uma organização formal diante das tarefas apresentadas nas salas de trabalho, assim como não solicita ao ator-bailarino conjecturar formalmente por muito tempo sobre o que irá fazer, mas antes, impulsionando-o a agir com pouca pretensão e mais desprendimento. Como procedimento, o Viewpoints aparece como o outro lugar onde amarramos a linha que parte do corpo como na metáfora da marionete, favorecendo o aparecimento de múltiplas informações que o sustentam e o mesmo faz com o ambiente em ação, nutridos por uma vontade pessoal e do interesse pela construção da obra poética.

8

Diz respeito ao conceito de Rizoma, concebido por Deleuze e Guatarri. "O conceito rizoma funciona como a porta de entrada ao pensamento deleuze-guattariano, porta cujo local de aparição é variável, indeterminado, vagamente dado, uma porta pela qual entramos e caminhamos a qualquer lugar destes platôs: qualquer ponto de um rizoma pode ser conectado a qualquer outro e deve sê-lo. O rizoma "(...) é feito de direções móveis, sem início nem fim, mas apenas um meio, por onde ele cresce e transborda, sem remeter a uma unidade ou dela derivar". (CABRAL; BORGES, 2008) 


\section{O CORPO LOTADO E NÃO MENOS ESPAÇADO PARA DEMAIS OCORRÊNCIAS}

Em um dado momento da pesquisa artística, o ator-bailarino se vê afastado pelo procedimento como atividade pura, com a única finalidade de exercitar e, encontra-se integrado em uma experiência cênica, que não deixa de ter um caráter ainda de estudo, mas que prioritariamente está voltada para uma outra realidade, que solicita ao corpo ser considerado em "si mesmo", tornando-o com isso, uma estrutura significativa e autônoma.

“É como corpo e numa presença corporal que eu sou conhecido pelo outro", afirmou o espanhol Pedro Entralgo (Apud JANA, 1995, p.52). Este entendimento ilumina a investigação aqui presente para reconhecer o procedimento artístico, no caso, o Viewpoints, como um ambiente provocador e gerador do estado de presença do artista, campo para conhecimento e integração com o outro e oportunidade para emergir a noção de "si mesmo", mediatizada pela presença do outro.

Portanto, a própria imagem que o corpo tem de si mesmo não é imediata, antes resulta de um processo de construção na e pela inter-relação corporalizada no mundo das coisas. (JANA, 1995, p.53)

A comunicação humana é amparada por gestos significativos que requerem interpretações constantes para gerar assimilação e progressão nas relações, assim, através de códigos cujos significados detêm compreensão mútua, os indivíduos compartilham entendimentos e experiências. Este tipo de comunicação desperta no outro um olhar detalhado sobre suas próprias ações:

O sujeito não é antes individual para depois tornar-se social: ele surge dialeticamente por meio da comunicação com os outros. [...] não pode haver sujeitos isolados, pois não pode haver um senso de "identidade do eu" sem o senso correspondente do 'outro'. (WERLE, 2008) 
A identidade surge como um modo singular de organizar a informação que empreende o encontro com o outro, promovendo com isso, a ativação de um processo de conhecimento, uma vez que novos conteúdos são levantados e requerem uma negociação com os já presentes, para encadear nexos de sentido que garantam sua vitalidade e sobrevivência.

Encarada a obra artística como um lugar de construção entre ator-bailarino/público, ela será sempre singular, no sentido que é representada por cada um envolvido na ação por recursos signicos peculiares e extremamente particulares. Assim, o espectador também está sob uma experiência corpórea, ainda que aparentemente estático em sua poltrona, afinal, ao compreender a obra, no sentido de misturá-la com seu universo, categoriza aquilo que vê, e assim, amplia suas possibilidades de organização porque entra em contato com novas informações. Este contatar com outras ações subsidia a formação da identidade, tanto daquele que demonstra como daquele que vê, já que ambos se complementam e estão sujeitos a remanejamentos referentes às suas formas de existir.

Os exercícios de improviso do Viewpoints possibilitam o surgimento (tanto da obra como um todo, assim como do artista em si) de certa reflexividade, onde os envolvidos na experiência permitem-se ser afetados pelos outros, numa mistura que gera reflexos nos corpos em ação, determinando novos caminhos para agir. A individuação é provocada com uma série de interferências tempoespaciais que exigem ações sem muita premeditação, ausente de "quereres" ou intenções mais específicas, mas sim, de impulsos amparados pela relação proposta com o outro.

Dentro da perspectiva levantada neste estudo a constituição da corporeidade do atorbailarino está num lugar que aparece entre o corpo e o ambiente como um todo, na provocação e lida com determinados estados, geradores de significados e compositores de uma dramaturgia. Condizente com um aparato histórico-pessoal, cada corporeidade assimila as informações trazidas pelo outro, possíveis pela premissa da sujeição a esta condição, comprometida com a formação do artista e do artista com a vida de forma mais compartilhada.

Retomando o conceito de Deleuze e Guatarri supracitados, se pode afirmar que a corporeidade se dá em estado rizomático, se este for pensado como um elemento que "procede por variação, conquista, captura, é heterogêneo, um mapa" (CABRAL; BORGES, 2008), que não acumula estoques estagnados, mas é permeado pela aventura de ser permanentemente recomposto, transitável e dinâmico. 
Aquilo que então especifica o padrão de ação de um ator-bailarino é atribuído à sua potencialidade de variar, conquistar e capturar o "entre" que emerge entre ele mesmo e o que lhe circunda. Estes verbos de ação agem plenos de particularidade, conferindo então ao atorbailarino, uma relação com o procedimento e uma escritura cênica própria e original.

Variar, conquistar e capturar, verbos emprestados da lógica deleuziana, empregados na convivência com o ambiente, vão compondo a qualidade no trabalho do intérprete-criador, possibilitando um reconhecimento de sua particularidade junto à conscientização sobre si mesmo, tanto no que confere a lida com o procedimento na sala de trabalho assim como a organização formal que recebe a obra de arte.

\section{BIBLIOGRAFIA}

BERNARD, Michel. De la création choréographique. Paris: Centre National de la danse, 2001. BOGART, Anne. LANDAU, Tina. The Viewpoints Book. A practical Guide to Viewpoints and Composition. New York: Theatre Communications Group, 2005.

CABRAL, Cleber; BORGES, Diogo. Rizoma: Uma introdução aos Mil Platôs de Deleuze e Guatarri. 2008. Disponível em: http://www.revista.criterio.nom.br/artigo-rizoma-mil-platosdeleuze-guattari-diogo-borges-cleber-cabral.htm.

DELEUZE / SPINOZA. Le Cour de Gilles Deleuze. Cours Vincennes. 24/01/1978. Disponível em: http://www.webdeleuze.com/php/texte.php?cle=194\&groupe=Spinoza\&langue=5

GREINER, Christine. O Corpo: Pistas para estudos indisciplinares. São Paulo: Annablume, 2005.

GREINER, Christine; AMORIM, Cláudia (orgs). Leituras do Corpo.São Paulo, Annablume, 2003.

JANA, José Eduardo Alves. Para uma Teoria do Corpo Humano: Apresentação e Crítica da Teoria do Corpo Humano de Pedro Laín Entralgo. Lisboa: Instituto Piaget, 1995.

WERLE, Denílson. Fundamentos para a compreensão contemporânea da psique. Revista Mente-Cérebro e Filosofia. Número 8, 2008. 